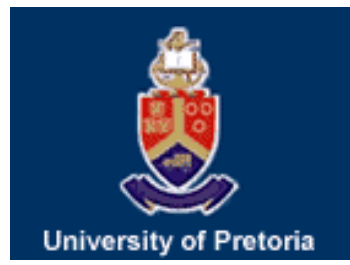

University of Pretoria Department of Economics Working Paper Series

Dynamic Health Care Decisions and Child Health in South Africa Olufunke A. Alaba University of Pretoria Steven F. Koch University of Pretoria Working Paper: 2008-34 October 2008

Department of Economics University of Pretoria 0002, Pretoria South Africa

Tel: +27 124202413

Fax: +27 123625207 


\title{
Dynamic Health Care Decisions and Child Health in South Africa
}

Olufunke A. Alaba ${ }^{*}$ and Steven F. Koch ${ }^{+}$

\begin{abstract}
A large number of child deaths in developing countries could be averted if ill children received care sooner rather than later. However, analysis in these developing countries rarely considers the pathway, through which, health care is sought at the household level. This paper considers two separate pathways of health-seeking decisions and finds that household controls affect decisions in different ways across the pathway; for example, different measures of female empowerment increase treatment, as well as preferences for private care along the pathway, but not consistently.
\end{abstract}

JEL: I12, D13, C35

\footnotetext{
- The authors would like to thank participants at the Income Distribution and the Family conference, for their thoughts on this paper. All remaining errors are the sole responsibility of the authors.

* Corresponding author. Postdoctoral Fellow, Health and Development Policy Research Group, Department of Economics, University of Pretoria, Pretoria, 0002, Republic of South Africa; (O) 27-12420-4504, (E) funkeal@yahoo.com.

+ Professor of Economics, Health and Development Policy Research Group, Department of Economics, University of Pretoria, Pretoria, 0002, Republic of South Africa; (O) 27-12-420-5285, (E) steve.koch@up.ac.za.
} 


\section{INTRODUCTION}

Despite heavy public investment and global health care initiatives, high child morbidity and mortality is still prominent in developing countries, and the illnesses behind the observed morbidity and mortality are largely preventable. ${ }^{1}$ Furthermore, the United Nations Children's Fund (UNICEF, 2007) estimates that as many as half of all child deaths could be averted through inexpensive health practices including better child healthcare decision-making. Souza et al (2000) find that poor and/or delayed healthseeking for children contributes up to $70 \%$ of child death; however, ensuring prompt and appropriate care-seeking is one of the practices for which there is the least health policy intervention experience (Hill et al 2003). Given that most children survive into adulthood, prompt and better health care decisions or other investments into child health are likely to have effects beyond averting childhood mortality and morbidity. Adler et al (1994), Case et al (2005) and Case et al (2003), for example, show that low levels of child health investments have far-reaching negative consequences to social, educational, economic, and health outputs for those children upon reaching adulthood.

One investment of particular relevance to this research is the set of decisions made on behalf of children, who depend on adult care-givers, typically parents, to act in their best interests. In other words, adult care-givers and the constraints they face within their household and family structures will strongly influence child health outcomes. ${ }^{2}$ As noted by Jacobsen (2000), the household does not only demand and consume health care, the household is also an important producer of prevention, health care and health, in general. In considering health care, for example, whether or not to use health services is a choice that households often have to make. Regardless of the nature of the health care need,

\footnotetext{
${ }^{1}$ Infant and childhood mortality rates are still as high as 91 per 1000 in developing countries, caused largely by infectious diseases, including Acute Respiratory Infections (ARI) and diarrhoea. Wagstaff (2004)

2 The family holds the primary responsibility for the protection, upbringing and development of children who are entitled to receive comprehensive protection and support. UNICEF (2001)
} 
Pokhrel et al (2004) suggest that health care decisions are complex processes involving several steps that are not an end in themselves; instead, as has been further argued by Cardol et al (2005) and Ha et al (2002), these complex decision processes are influenced by various, sometimes independent and sometimes interwoven, factors.

Among the several models for explaining health seeking behaviour and its surrounding complexity, two basic approaches have been identified. Kroeger (1983) distinguishes these two approaches as the pathway model and the determinants model. The pathway model assumes a logical sequence of steps, e.g., decisions are taken from the earliest symptoms through to the decision to use health care services, as well as which type of service. The pathway model or "illness career" approach has its roots in medical sociology and anthropology, and, as its name implies, represents a dynamic process. ${ }^{3} \mathrm{~A}$ number of qualitative methodological approaches have modelled the health care utilization decision-making process by elaborating on patient action and interaction, as well as the stages or pathways that result in facility contact. ${ }^{4}$ However, quantitative evidence underpinning the aforementioned qualitative decision process has been sparse. The determinants model, on the other hand, focuses on variables explaining preferred health care service choices, and tends to be a static analysis focusing on one particular decision within the decision-making process. Current empirical literature has identified some demand (e.g, family headship, age, gender of family head, employment status and education level of the parent, availability of social protection, quality of the services and income) and supply (e.g., prices and health facility characteristics) factors that affect

\footnotetext{
${ }^{3}$ Pescosolido (1992) defines the "illness career" as the sequence of actions surrounding the rectification of a health problem.

${ }^{4}$ Suchman (1965) was first to describe the process of illness behaviour as a logical sequence of steps, beginning with the perception and evaluation of symptoms and concluding with the use of different health facilities.
} 
decisions to utilize health facilities. ${ }^{5}$ Salgado De Snyder et al (1998), however, note that most quantitative research on health-seeking behaviour has focused on identifying and describing the barriers to health services utilization as the end-point of the analysis, and, thus, failed to offer empirical evidence at any decision node along the pathway, except at the final health services contact node.

In a pluralist medical setting, people can choose what to do first, second, third, etc., from a variety of treatment options, suggesting that people's choices can be represented as an ordered series of health-related behaviours. Therefore, a sequential analysis of the data may provide insights into caregiver behavioural patterns and suggest ways to improve the medical choices made by caregivers. Conceptually, the idea behind sequential decision making is fairly simple: choice options are likely to be affected by preceding choices. Thus, the pathway or sequential framework assumes that health care decisions are part of a progressive process affected by factors likely to vary as the process unfolds ( $\mathrm{Ha}$ et al, 2002; Pokhrel et al, 2004, 2005).

In this paper, we examine a pathway model of health-seeking behaviour for children under the age of five, where the behavioural decisions are likely to be driven by adult caregivers, as well as household resource and structure constraints. The analysis is considered within a sequence of health-seeking behavioural events, from detection of child illness, to the decision to seek treatment, either immediately or later, to the facility sought for treatment. A sequential logit model is applied to World Health Survey (WHS) data collected in South Africa in 2003 (WHO, 2003) to estimate our pathway model. The goal of the empirical exposition is to discern structures (e.g., caregiver

\footnotetext{
${ }^{5}$ Ensuring the availability of essential supplies, equipment and medication is a necessary requirement for good quality health care. However, child survival, growth and development depend not only on the food intake and health but also on care-giver behaviours, Engle et al (1997).
} 
marital status and household size), household resource constraints and illness severity that describe households during a child's illness episode, as well as any strategies or sequences that the household might follow during the episode.

The rest of the paper is organized as follows. We continue, in Section 2, by describing the pathway model that we use in the analysis. Section 3 describes the data used in the analysis. The results of the analysis are presented in Section 4, while Section 5 concludes and considers potential avenues of future research.

\section{METHODOLOGY}

\subsection{The Pathway Model of Health Care Choice}

We consider a pathway model of a child's illness career as the basis for the empirical exposition in this paper. The pathway model assumes that decisions regarding child health care are dynamic in nature and influenced by household characteristics, especially the involvement of the parents. The importance of parental resources, behaviour and household structure on a child's health is evident in the large differences that exist in children's health outcomes. ${ }^{6}$ The nodes we consider along the pathway are: the perception or recognition of child illness, although that is not a major feature of the analysis, the decision to seek treatment or not, the length of time preceding treatment, and the medical care contact stage. Although each of these stages is considered within a different sequence, such that order is model specific, their primary features are essentially the same across the models. Each of these factors is discussed in turn, below.

\footnotetext{
${ }^{6}$ Lindelow (2004) found that a biological child of the head of the household is more likely to be immunized. Similarly, Astone and McLanahan (1991) found that children receive less parental time and attention in single parent families. While, Coreil (1983) observed, in the case of rural Haiti, that the opportunity cost of taking children to health facilities is greatest in single-adult households.
} 
The perception or recognition of illness is the first important stage in the sequence of health care. According to Suchman (1965), problem identification occurs at this stage and without that identification no health care would be sought. Perez-Cuevas et al (1996), Bojajil (2002) and Pokhrel (2004) have all identified symptom recognition and perception as a barrier to care-seeking. ${ }^{7}$ However, in order to place the child in an "illness career", the child must be accepted in the sick role. Acceptance into this role, as noted by Taffa et al (2005), depends primarily upon maternal recognition of certain signs and symptoms of child illness, such as illness severity. ${ }^{8}$

Another set of steps in the health decision trajectory is tied into investments in health recovery, either through the consultation of an external health worker or through natural recovery and the timing of that investment. Thus, the household is assumed, at this stage, to make a complex decision that is revealed through the timing of their health-seeking behaviours. The decision is assumed to be consistent with its utility maximization objective, subject to the household budget constraint; however, it is likely to be quite dynamic, even at this stage. For example, the household may initially decide to allow the child to recover naturally, but observes a few days later that the child has not naturally recovered to the degree expected; such an observation would likely result in a treatment decision update that we would only be able to observe as delayed treatment. This step in the decision trajectory, however, is important, since a number of childhood diseases leading to death could be reduced if appropriate treatment was given in a timely manner. ${ }^{9}$

\footnotetext{
7 Pokhrel et al (2004) indicate that differential child mortality in Nepal may be due to differential health care access arising primarily from illness perception, not necessarily from the decisions to seek care or spend money on sick children.

${ }^{8}$ Teerawichitchainan et al (2008), in their multinomial logit study of Vietnam, discovered that child sex, ethnicity, the number of siblings and maternal education are important determinants of reported illness. ${ }_{9}^{9}$ Bojalil (2002) and Hill et al (2003) focus upon the potential reduction in deaths that could results amongst both the large number of children who die in developing countries without reaching a health facility, and the large number who die shortly after arrival at healthcare facilities if treatment delay were reduced.
} 
The medical care contact stage is the final leg of the path to be discussed; in a wide variety of analyses, it is the only step in the path to be considered. ${ }^{10}$, in which households are assumed to make use of a knowledgeable health care provider from either the public or private sector. Although this is the last stage of the household analysis in our model, due to data considerations, it is likely that the healthcare provider will present additional decisions related to treatment and treatment compliance (Homedes et al, 2001; Fadil et al, 2003).

\subsection{The Econometric Model}

We consider two rather different analyses; in one the treatment or no treatment decision is taken early, while in the second the no treatment decision is a result of not undertaking any treatments, and, therefore comes last. Although each approach is logically consistent, each approach offers different interpretations. The first analysis that we consider is based upon Figure 1. In that figure, the assumed sequence is: (1) reported illness, (2) treatment, (3) facility treatment choice and (4) the timing of treatment at that particular type of facility. In that framework, the probability of no treatment becomes $1-p$, the probability of immediate treatment at a public facility becomes $p q h$, while the probability of delayed treatment at a public facility becomes $p q(1-h)$. For private facilities, immediate treatment occurs with probability $p(1-q) g$, while delayed treatment occurs with probability $p(1-q)(1-g)$.

\section{Figure 1 insert here}

The second analysis that we consider is based upon Figure 2, which is a re-ordering of the sequence based upon timing, and, therefore it cannot be directly tested against the

\footnotetext{
${ }^{10}$ See, for example, Grobler and Stuart (2007), Bolduc, LaCroix and Muller (1996) and Dor, Gertler and Van der Gaag (1987) for Africa specific examples of health facility choice focusing specifically on a single component of the decision tree.
} 
sequence presented either in Figure 1. Despite that, the sequence is logically derived from the observed timing of treatment. The ordering of events is (1) reported illness, (2) immediate treatment in a public facility, (3) immediate treatment in a private facility, (4) delayed treatment in a public facility, (5) delayed treatment in a private facility and (6) infinite delay, or no treatment. In that analysis, the probability of immediate public treatment becomes $h$. For immediate treatment options, the probability of immediate private treatment becomes $(1-h) g$, while the probability of delayed public treatment becomes $(1-h)(1-g) q$. In terms of the final treatment options, the probability of delayed private treatment becomes $(1-h)(1-g)(1-q) p$, while the probability of no treatment, or infinite delay, becomes $(1-h)(1-g)(1-q)(1-p)$.

\section{Figure 2 insert here}

The novel empirical aspect of this paper lies in the application of a sequential model, which can be classified with other generalized extreme values models. When looking at the structural model designs, two modelling choices - multinomial and sequential models - are most useful, although a more general and flexible modelling approach would allow for nesting. However, nested models do not define the process of decision-making; rather, they only account for differences in variances in the unobservable utility components (Hensher et al., 2005).

Given the sequential nature of two figures, it is natural to consider a sequential empirical model. Such models have a lengthy history in the literature. Amemiya (1975) first described the sequential probit and logit models for ordered discrete alternatives, based on the random utility theory. Shortly thereafter, Heckman and Willis (1977) analyzed sequential labor force participation by married women, exploring heterogeneity among 
women in their sample. Although the empirical model has a lengthy history, it has not been widely applied in the analysis of health care decisions, despite the sequential nature of health care decisions. Importantly, acknowledgement of a child's illness, the timing of treatment and medical facility contact are not necessarily jointly determined.

In order to understand the main determinants contributing to each decision node along the pathway, we make use of a sequential bivariate choice model. The probability that the household $b$ chooses a decision alternative $j$ equals the probability that the utility derived from alternative $j$ is greater than that of any other alternative (Amemiya, 1981; McFadden, 1974, 1981). The specification of a sequential logit model allows the choices between two discrete alternatives to depend on a set of covariates that consist of socioeconomic variables, health facility and family structure related factors, which we will denote by $X$. The sequential outcomes consider that a probability of an event will occur given that another event had occurred prior to that outcome.

Given that our data does not allow us to consider reported illness too closely, the broad probabilities used in the analysis are: $p$ - probability of treatment, $q$ - probability of public facility choice, $h$ - probability of delay, conditional on public facility, and $g-$ probability of delay conditional on choosing a private health facility. These broad probabilities are modelled on the following probability functions: $p=\Lambda_{p}\left(-X \beta_{p}<\varepsilon_{p}\right)$, $q=\Lambda_{q}\left(-X \beta_{q}<\varepsilon_{q}\right), h=\Lambda_{h}\left(-X \beta_{h}<\varepsilon_{h}\right)$ and $g=\Lambda_{g}\left(-X \beta_{g}<\varepsilon_{g}\right)$ to fit within the standard latent variable framework, where $\Lambda_{i}$ is the relevant logistic function. In all of the analyses, there are six exit points. The first occurs if there is no illness, another occurs when no treatment is sought, while the remaining exit points are related to the 
underlying facility choices either with or without delay. The seqlogit program in STATA developed by Buis (2007) was used to estimate the model.

\section{DATA AND ANALYSIS VARIABLES}

\subsection{The WHS}

The data for this study is taken from the World Health Survey (WHS) carried out in 70 countries during 2002-3. The survey was developed and implemented by the World Health Organization, in order to compile valid, reliable and comparable comprehensive information on the health of the population and on the outcomes associated with investments in various national health systems, Usten et al (2001). The survey is primarily designed to develop an evidence based data set to monitor whether health systems are achieving their desired goals, as well as to provide the evidence base that policymakers need to improve their policies, strategies and programs, WHS (2003). Data in the WHS was collected on a modular basis. The modules address different aspects of the health system and include information on health insurance, health expenditures, socio-demographics, income, health state evaluations, health system responsiveness and health system goals.

A study carried out to examine the feasibility of using the WHS data to measure medicine need, use and out-of pocket expenditures in eight low- and middle-income countries concluded that WHS data collection procedure and result files were consistent. Wagner et al (2007) judged the overall quality of the data to be satisfactory for any quantitative analysis that could be considered. Similarly, Obermeyer et al (2008) used the data to analyze fifty years of violent war deaths from Vietnam to Bosnia. The reliability of the WHS was tested, primarily through a comparison with other sources of war data and documentation, such as that provided by the Research and Documentation Centre in 
Sarajevo, which has compiled a high quality historical database on war deaths, and that provided by Uppsala University and the Peace Research Institute Oslo (Uppsala/PRIO). The results indicated that localization in time of death captured by the WHS data is largely consistent with patterns and trends in the other two sets of data. In addition to cross-country studies, the data has also been used, albeit in limited instances, to focus on specific countries, like South Africa. ${ }^{11}$

Based on the reliability of the WHS data observed by previous researchers, our analysis makes use of the WHS 2002-3 South Africa Survey, which consists of 2345 households and 10500 individuals. However, the WHS does have its limitations. The main one being that the econometric analysis is applied on a reduced sample of one under-five child per household, due to the lack of detailed health care decisions and outcomes information on other children and older children within the household. The final analysis data set consisted of 313 households with observed child illnesses and complete independent data.

\subsection{Analysis Variables}

The empirical model assumes that households maximize utility by following a healthcare pathway, for the sake of children under the age of five, and the empirical specification includes various socioeconomic and demographic characteristics of the household. Pokhrel et al (2004) observe that, although female heads are more likely to perceive and report a child's illness, they are less likely to seek any care, possibly because of reduced access to resources. It is likely that greater autonomy allows a mother to respond to a child's illness by seeking adequate medical treatment and care. Duflo (2003) finds that empowered women (pension recipient South African women, particularly) are more

\footnotetext{
${ }^{11}$ Lamiraud et al (2005) analysed the impact of social health protection on access to health care, health expenditure and impoverishment in South Africa using the WHS 2002-3 data.
} 
likely to focus their resources on younger children than men. Furthermore, there is a strong positive relationship between education and health, as noted by, for example, Lindelow (2005). Lindelow (2004), Fosu (1994) and Chakraborty et al (2003) find a positive relationship between a women's autonomy, using education as a proxy, and child health outcomes. Therefore, the sex of the household head, as well as a measure of household female empowerment, based on education received by females in the household, are included in the analysis. An additional measure of education used in this study is a dummy variable indicating the primary school attainment by the household head.

Economically, we also expect family income to affect household health decisions. As shown by Anyanwu (2007), Dong et al (2008) as well as Novignon and Aglobitse (2008), for example, income is a strong predictor of facility choice in developing countries. Although access to household income is likely to important, as already noted, we include per capita expenditure (and its square) as a proxy for household income in this study. Other variables used in this study to control for preferences include family size, marital status of the head and the observed illness symptoms. ${ }^{12}$

\subsection{Descriptive Analysis}

Before turning to the empirical analysis, we provide a brief breakdown of survey data across a general four-stage child health decision pathway to highlight differences in household characteristics throughout the pathway. The average age of the children under five in this sample is 3.4 years; however, the children are categorized as minor infants (0-2 years) and elderly infants (3-5 years).

\footnotetext{
12 Although, all symptoms included in the survey were separately considered in the analysis, combinations of fever and vomiting were more commonly statistically significant, and, therefore, retained in the analysis presented here.
} 


\subsubsection{Perceived Illness and treatment seeking stage}

At the first step, the elderly infants are more likely to report illness (73\%) and to receive some form of treatment (89\%) than the minor infants; however, the minor infants suffer less delay in treatment action than the elderly infants $-70 \%$ of the minor infants receive prompt action compared to $67 \%$ of the elderly infants. For children with no direct relationship to the household, they were 3\% less likely to be reported compared to their directly related counterparts. For household heads with no education, only $9 \%$ of the children were reported to be ill, compared to $35 \%$ of the children whose household heads had attended high school or beyond. The same trend could be observed regarding treatment conditional on reported child illness. In the sample, $9 \%, 21 \%$ and $36 \%$ of children received some form of treatment if the household head had no education, uncompleted primary education and at least a high school education, respectively. Relatively speaking, children from male-headed households were slightly more likely to be reported as ill than those in female-headed households - $74 \%$ compared to $71 \%$, although that is likely to be due to the fact that more children are in male-headed than female-headed households. However, when it comes to treatment, female-headed households are more likely to attend to treatment than male-headed households $-89 \%$ to $85 \%$. Across income quartiles, the patterns are not easily discerned, although ill children are more likely to receive treatment the higher the income quartile. Finally, fever, cough and diarrhoea appear to be high priority symptoms, in terms of treatment, although all cases where the child was observed either vomiting or convulsing were treated. 


\subsubsection{Delay in treatment action}

In the data, delay appears to be less likely amongst female-headed households $-69 \%$ of the children compared to $67 \%$ in male-headed households. As with reporting and treatment, in general, education is associated with less delay - only $9.5 \%$ of children, whose household head was uneducated, underwent prompt treatment compared to $36.6 \%$ of children, whose household head had received at least a high school education. In terms of income, the lowest income quartile had the lowest percentage of children $(22.5 \%)$ receiving treatment without delay; the bottom half, on the other hand, contributed $55.2 \%$ of the children who received delayed treatment. In terms of diseases and symptoms, nearly all diseases received prompt attention, meanwhile $100 \%$ of the children received prompt treatment if they were observed with blood in their stool. A sick child in a female-headed household is less likely to be treated, externally, compared to the child in the male-headed household $-13.9 \%$ compared to $16.1 \%$.

\section{$\underline{\text { 3.3.3 Treatment provider decision }}$}

Given the South African health system, it is not surprising that public clinics are the most utilized facility, although public clinics are followed closely by private clinics. However, indirectly related children are highly concentrated in public clinics $(54.7 \%)$ while directly related children are concentrated in private clinics $(46.0 \%)$ Female heads of household are more likely to use public facilities, while the male heads of household are more likely to use a private facility. Furthermore, there is a very significant shift towards private facilities, as the household falls into a higher income groups. ${ }^{13}$

\footnotetext{
${ }^{13}$ However, as noted by Burger et al (2006), households in the low income quartiles also make significant use of private facilities in South Africa.
} 


\section{RESULTS}

As noted in the methodologies section, two distinct sequential models were considered in the analysis. In one of them, treatment, and, therefore, non-treatment, was the initial decision, while in the other, not treating was a result of a sequence of decisions to not treat at any particular place or time. Although both sequences are logically consistent, they are not obviously statistically comparable. Each also offers a slightly different interpretation surrounding household decisions related to the treatment of children, who have become ill.

\subsection{An Empirical Examination of Figure 1}

The results from the initial empirical model, based upon Figure 1, are presented in Table 2. In that analysis, the initial decision, to treat or not, is shown to be strongly influenced by symptoms of illness, as both observed vomiting and observed fever increase the probability of treatment. Furthermore, household size, female headship and female status, as measured by the proportion of educated females in the household, also increase the probability that treatment will be sought at the outset, although a single parent is less likely to seek treatment. However, income is only more likely to raise the probability of treatment if we are willing to go past conventional levels of significance.

Once treatment has been determined, the next decision in our tree is the general choice of health facility, either public or private. In our analysis, choosing to use a public facility over a private facility, conditional on treatment, is more likely if households expected a courteous staff at the facility, females in the household were working and if the child was feverish. On the other hand, if the household head had received primary education, public sector facilities were more likely. 
Following the facility decision, which had been further conditioned on the treatment choice, households were expected to choose between delaying treatment or seeking immediate treatment. The analysis presented here, however, did not differentiate between delay outcomes for those households using the public sector. ${ }^{14}$ Within households making use of the private sector, immediate treatment was more common for fever, higher per capita expenditure (although entering in a concave fashion) and a larger proportion of educated females in the household. In terms of households expected perception of staff courtesy, increases in that perception were more likely to be associated with households that had sought immediate treatment.

\subsection{An Empirical Examination of Figure 2}

The results of the second empirical analysis undertaken in the paper, which is based upon Figure 2, are presented in Table 3. The initial decision in the second analysis was whether or not to immediately seek treatment in a public facility or to do something else; however, that choice was not broadly influenced by many of our analysis variables, except the receipt of primary level education by the household head, which made immediate treatment at a public facility less likely.

For those households with ill children that decided not to attend a public facility immediately, their next course of action was to consider, instead, seeking immediate treatment at a private facility or doing something else. Conditional on not seeking immediate treatment in a public facility, households with more per capita expenditure (although the result is concave), a higher proportion of educated females, a female head and a feverish child were more likely to seek immediate treatment.

\footnotetext{
${ }^{14}$ We did consider a special case of this analysis, in which the delay component, under public facilities, was included. The resulting likelihood ratio statistic of $\chi_{12}^{2}=7.60<\chi_{12}^{2}$ (critical, 0.05$)=18.31$ was not significant and, therefore, we chose to remove the delay decision, under the public sector, in the analysis.
} 
For those that did not seek immediate treatment either at a public facility or at a private facility, were assumed to have made a delayed decision, and their first delayed option was to make use of the public sector. The results point to the conditional probability of delayed public health facility usage as decreasing in income, but more likely for single parents.

Finally, households that had not sought any treatment so far, according to this decision tree, were allowed to make one final choice. That final conditional choice was whether or not to seek private treatment, even though the decision had been delayed, or to not seek any treatment at all. Although few of the variables were significant, they were all generally negative, suggesting that at least some form of conditional treatment is better than none, a directional result that is statistically significant for households with working females or a child observed to be vomiting.

\section{DISCUSSION AND CONCLUSIONS}

Empirically, a similar four-stage analysis was examined by Pokhrel et al (2004) via both binary and multinomial logit. In their analysis, they found that the gender of the household head was a significant determinant at the illness perception level, although the significance of the household head gender subsequently diminished, especially with regards to provider choice and health care expenditure. ${ }^{15}$ In the literature, women have been identified as the party responsible for identifying illnesses, and also deciding on the sort of treatment to give within the home; however, gender roles often require that the woman consult the husband or other male in the household, when it comes to pursuing

\footnotetext{
15 UNICEF (1990) and Vlassoff et al (1995) pointed to the paradox that while women as the main caretakers are the first in perceiving illness in children, they often lack the means to adequately act, because they depend on the men who control the funds.
} 
external treatment (Tolhurst, 2008). Therefore, female access to resources may be an important factor that influences child treatment seeking decisions by female caregivers. Our Figure 1 results were similar, in that the gender of the household head appears only to influence the decision to seek treatment or not, and not other aspects of the decision process. Furthermore, our results also show that female access to resources, either because of working or through education, identifies a preference to seek treatment, use private health facilities instead of public facilities, and to seek treatment at the private facilities immediately. Our figure 2 results also provided interesting insights into gender and gender access to resources. According to Table 2, the female heads of household were less likely to immediately seek out public facility care, although not affecting any other transition. Female access to resources, on the other hand, also reduced the probability of immediately seeking public facility care, while also making conditional nontreatment less likely.

Sharma's (2008) hazard analysis of malaria patents in Nepal found that patient age, household size, education and travel time did not significantly affect the probability of taking care. Our results related to the education level of the household head and the household size were more varied. In Figure 1, the education level of the household head does not affect treatment, although it does increase the conditional probability of private facility usage, while reducing delay conditional on using private services. A larger number of people within the household, on the other hand only increases treatment in Figure 1, while in Figure 2, household size reduces the probability of that treatment being immediate use of private facilities, given that public facilities were not immediately used. Similarly, education of the household head only serves to reduce the probability that the child is treated immediately in a public facility. 
Overall, the two sets of results point to large differences related to the decision process as modelled here. Our results show that income does not generally affect treatment, although it does affect decisions in which income is likely to be more important, i.e., the location and timing of that treatment. Furthermore, our results do point to differences in and difficulties related to the ability of female household heads and other empowered females in the household to influence the child health care decision trajectory, although there are decision points at which they certainly have more influence. In other words, failure to capture the health care decision-making process, by examining only one stage in the process, is likely to bias the analysis and is unlikely to identify the step or steps (in the process) where health care interventions could play a substantial role in improving health outcomes. In our analysis, for example, we have not been able to identify differences in household treatment delay, conditional on public health choice, suggesting that households do not view South African public health facilities favourably, when it comes to alleviating immediate health concerns.

The current research has focused only upon South African households. However, a large number of additional countries were also surveyed by the World Health Organization, such that this analysis could be repeated across a number of regions in the world. Although countries are not likely to be completely homogeneous, a pooled model might improve the precision of the underlying estimates, and if the pooled countries were carefully selected, the results might lend themselves to stronger policy conclusions. 


\section{REFERENCES}

Adler, N.E., Boyce, T., Chesney, M.A. , Cohen, S., Folkman, S., Kahn, R.L. \& Syme, S.L. 1994, "Socioeconomic status and health: the challenge of the gradient", American Psychologist, pp. 15-24.

Astone, N. \& McLanahan, S. 1991, "Family Structure, Parental practices and High school completion", American Sociological Review, vol.56,no. 3, pp.309-320.

Amemiya, T. 1975, "The nonlinear limited-information maximum-likelihood estimator and the modiped nonlinear two-stage least-squares estimator", Journal of Econometrics, vol. 3,pp. 375-386.

Amemiya, T. 1981, "Qualitative Response Models: A Survey", Journal of Economic Literature, vol. 19,pp. 1483-1536.

Anyanwu, J.C. 2007, "Demand for Health Care Institutions' Services: Evidence from Malaria Fever Treatment in Nigeria", African Development Review/Revue Africaine de Developpement, vol. 19, no. 2, pp. 304-334.

Ben-Akiva, M. \& Lerman, S. 1985, Discrete Choice Analysis: Theory and Application to Travel Demand. (Cambridge, MA: MIT Press).

Bojalil1, R., Kirkwood, B.R., Bobak, M. \& Guiscafre, H. 2007, “The relative contribution of case management and inadequate care-seeking behaviour to childhood deaths from diarrhoea and acute respiratory infections in Hidalgo, Mexico", Tropical Medicine and International Health, vol.12, no. 12, pp. 1545-1552.

Bolduc, D., Lacroix, G. \& Muller, C. 1996, "The Choice of Medical Providers in Rural Benin: A Comparison of Discrete Choice Models", Journal of Health Economics, vol. 15, no. 4, pp. 477-498.

Buis, M. L. (2007), "SEQLOGIT: Stata module to fit a sequential logit model” http://ideas.repec.org/c/boc/bocode/s456843.html 
Cardol, M. , Groenewegen, P. P., De Bakker, D. H., Spreeuwenberg, P., van Dijk, L. \& van den Bosch, W. 2005, “ A retrospective cohort study Shared help seeking behaviour within families" BMJ.

Case, A. ,Lubotsky, D. \& Paxson, C., 2002, "Socioeconomic status and health in childhood: the origins of the gradient", American Economic Review, vol.92,no. 5, pp. 13081334.

Case, A., Fertig, A. \& Paxson, C. 2005, "The lasting impact of childhood health and circumstance", Journal of Health Economics,vol.24,no.2,pp. 365-389

Chakraborty, N., Islam, M., Chowdhury, I., Bari W. \& Akhter, H. 2003, "Determinants of the use of maternal health services in rural Bangladesh", Health Promotion International, vol.18, no.4, pp.327-338.

Coreil, J. 1983, "Allocation of family resources for health care in rural Haiti", Social Science \& Medicine, vol.17, no.11, pp. 709-719.

Dong, H., Gbangou, A., De Allegri, M., Pokhrel, S. \& Sauerborn, R. 2008, "The Differences in Characteristics between Health-Care Users and Non-users: Implication for Introducing Community-Based Health Insurance in Burkina Faso", European Journal of Health Economics, vol. 9, no. 1, pp. 41-50.

Dor, A., Gertler, P. \& van der Gaag, J. 1987, "Non-price Rationing and the Choice of Medical Care Providers in Rural Cote d'Ivoire", Journal of Health Economics, vol. 6, no. 4, pp. 291-304.

Duflo, E. (2003), “ Grandmothers and granddughters: old-age pensions and intrahousehold allocation in South Africa", The World Bank Economic Review, vol. 17,no.1, pp.1-25.

Engle, P.L., Menon, P. \& Haddad, L. 1997, "Care and Nutrition: Concepts and Measurement", IFPRI Occasional Papers, Washington, DC. 
Fadil, S.M.A, Alrahman, S.H.A, Cousens, S., Shadoul, A., Bustreo, F. \& Farhoud, S. 2003, "Family compliance with referral and follow-up recommendations under the integrated management of childhood illnesses (IMCI) strategy, Gezira State, Sudan”, Bull World Health Organ., vol. 81,no. 10,pp. 708-716.

Fosu, G. B. 1994, "Childhood morbidity and health services utilization: cross-national comparisons of user-related factors from DHS data", Social Science and Medicine, vol.38,pp. $1209-1220$

Grobler, C. \& Stuart, I.C. 2007, "Health Care Provider Choice", South African Journal of Economics, vol. 75, no. 2, pp. 327-350.

Ha, N.H., Berman, P. \& Larson, U. 2002, "Household utilization and expenditure on private and public health services in Vietnam", Health Policy and Planning, vol. 17, no. pp. $61-70$.

Heckman, J J. \& Willis, R. J. 1977, “ A Beta-logistic Model for the Analysis of Sequential Labor Force Participation by Married Women”, Journal of Political Economy, vol. 85, no1, pp. $27-58$.

Hensher, D.A., Rose, J.M \& Greene, W.H. 2005, “Applied Choice Analysis”. Cambridge University Press.

Hill, Z., Kendall, C., Arthur, P., Kirkwood, B. and Adjei, E. 2003, "Recognizing childhood illnesses and their traditional explanations: exploring options for care-seeking interventions in the context of the IMCI strategy in rural Ghana", Tropical Medicine \& International Health, vol. 8, no. 7, pp.668-676.

Homedes, N. \& Ugalde, A. 2001, "Improving the use of pharmaceuticals through patient and community level interventions”, Social Science \& Medicine, vol. 52, no.1,pp. 99-134

Jacobson, L. 2000, "The family as producer of health-an extended Grossman model”, Journal of Health Economics, vol. 19. 
Kroeger, A. 1983, "Anthropological and Socio-medical Health Care Research in Developing Countries”, Social Science and Medicine, vol .17, no.3, pp. 147-161.

Lamiraud K., Booysen F., Scheil-Adlung X. 2005. The Impact of Social Health Protection on Access to Health Care, Health Expenditure and Impoverishment: A Case Study of South Africa. Unpublished research paper

Lindelow, M. 2004, "Health care decisions as a Family Matter: Intrahousehold Education Externalities and the Utilization of Health Services", World Bank Policy Research Working Paper, 3324

Lindelow, M. 2005, "The Utilization of Curative Healthcare in Mozambique: Does Income Matter?", Journal of African Economies, vol.14, no.3, pp.435-482.

McFadden, D. 1974, "Conditional logit analysis of qualitative choice behavior", In: Zarembka P (ed) Frontiers in econometrics, pp. 105-142.

McFadden, D. 1981, "Econometric Models of Probabilistic Choice”, In: Manski CF, McFadden D (eds) Structural Analysis of Discrete Data with Econometric Applications, The MIT Press, Cambridge, pp. 198-272

Negussie, T. and Chepngeno, G. 2005, "Determinants of health care seeking for childhood illnesses in Nairobi slums",Tropical Medicine \& International Health, vol. 10, no. 3, pp.240-245.

Nonvignon, J. \& Aglobitse, P.B. 2008, "The Choice of Health Care Services by Households in Selected Regions of Ghana", Ghana Policy Journal, vol. 2, no. 1, pp. 34-50.

Obermeyer, Z., Murray, C. J L. \& Gakidou, E. 2008, "Fifty years of violent war deaths from Vietnam to Bosnia: analysis of data from the world health survey programme", BMJ, vol. 336:, pp. 1482-1486.

Perez-Cuevas, R., Guiscafre, H., Romero, G., Rodriguez, L., \& Gutierrez, G. 1996. "Mothers' health-seeking behaviour in acute diarrhoea in Tlaxcala, Mexico", Journal of Diarrhoeal Disease Research, vol.14, no. 4, pp. 260-268. 
Pescosolido, B.A. 1992, "Beyond rational choice: The social dynamics of how people seek help", The American Journal of Sociology, vol.97, no.4, pp. 1096-1138.

Pillai, R., Williams, S. \& Glick, A. 2003, "Factors affecting decisions to seek treatment for sick children in Kerala, India", Social Science and Medicine, vol. 57, no.5, pp.783-790.

Pokhrel, S. \& Sauerborn, R. 2004, "Household Decision-making on child health care in developing countries: The case of Nepal", Health Policy and Planning, vol. 19, no.4, pp.218233.

Pokhrel, S ., Snow, R ., Dong, H ., Hidayat, B .,. Flessa, S. \& Sauerborn, R . 2005, "Gender role and child health care utilization in Nepal", Health Policy, vol.74, no.1, pp.100 -109 .

Salgado De Snyder, V.N., Diaz-Perez, M. J., Maldonando, M. \& Bautista, E. M. 1998, 'Pathways to mental health services among inhabitants of a Mexican village', Health \& Social Work, vol. 23, pp.249-261.

Sharma, V. 2008, "When to seek health care: A duration analysis for malaria patients in Nepal”, Social Science \& Medicine, vol. 6, no.12, pp. 2486-2494.

Suchman, E. A. 1965, 'Stage of illness and medical care', Journal of Health and Human Behaviour, vol.6, pp. 114-128.

Terra de Souza, A. C., Peterson, K. E., Andrade, F. M. O., Gardner, J. \& Ascherio, A. 2000, "Circumstance of post neonatal deaths in Ceara, Northeast Brazil: Mothers health-care seeking behaviours during their infants' fatal illness", Social Science \& Medicine, vol. 51, no. 11, pp. 1675-1693.

Teerawichitchainan, B. \& Phillips, J.F. 2008, “Ethnic differentials in parental health seeking for childhood illness in Vietnam", vol.66, no. 5, pp. 1118-1130.

Tolhurst, R., Amekudzi, YP., Nyonator, K. F., Squire, B. \& Theobald, S. 2008, "He will ask why the child gets sick so often": The gendered dynamics of intra-household 
bargaining over healthcare for children with fever in the Volta Region of Ghana", Social Science \& Medicine, vol. 66,no. 5,pp. 1106-1117.

UNICEF. 1990. Strategy for Improved Nutrition of Children and Women in Developing Countries. UNICEF Policy Review Paper UNICEF, New York.

UNICEF. 2001 A World fit for children.

Downloaded from unicef.org/specialsession/documentation/a-ac-256-crp-6-rev3.pdf.

UNICEF. 2004. Progress for Children. A child survival report card. vol.1, United Nations Children Fund.

UNICEF. The state of the world's children 2007. United Nations Children Fund.

Wagstaff, A., Bustreo, F., Bryce, J. \& Claeson, M. 2004, "Child Health Reaching the Poor", American Journal of Public Health, vol.94, no.5, pp.726-736.

World Health Organization: The World Health Survey 2003. 


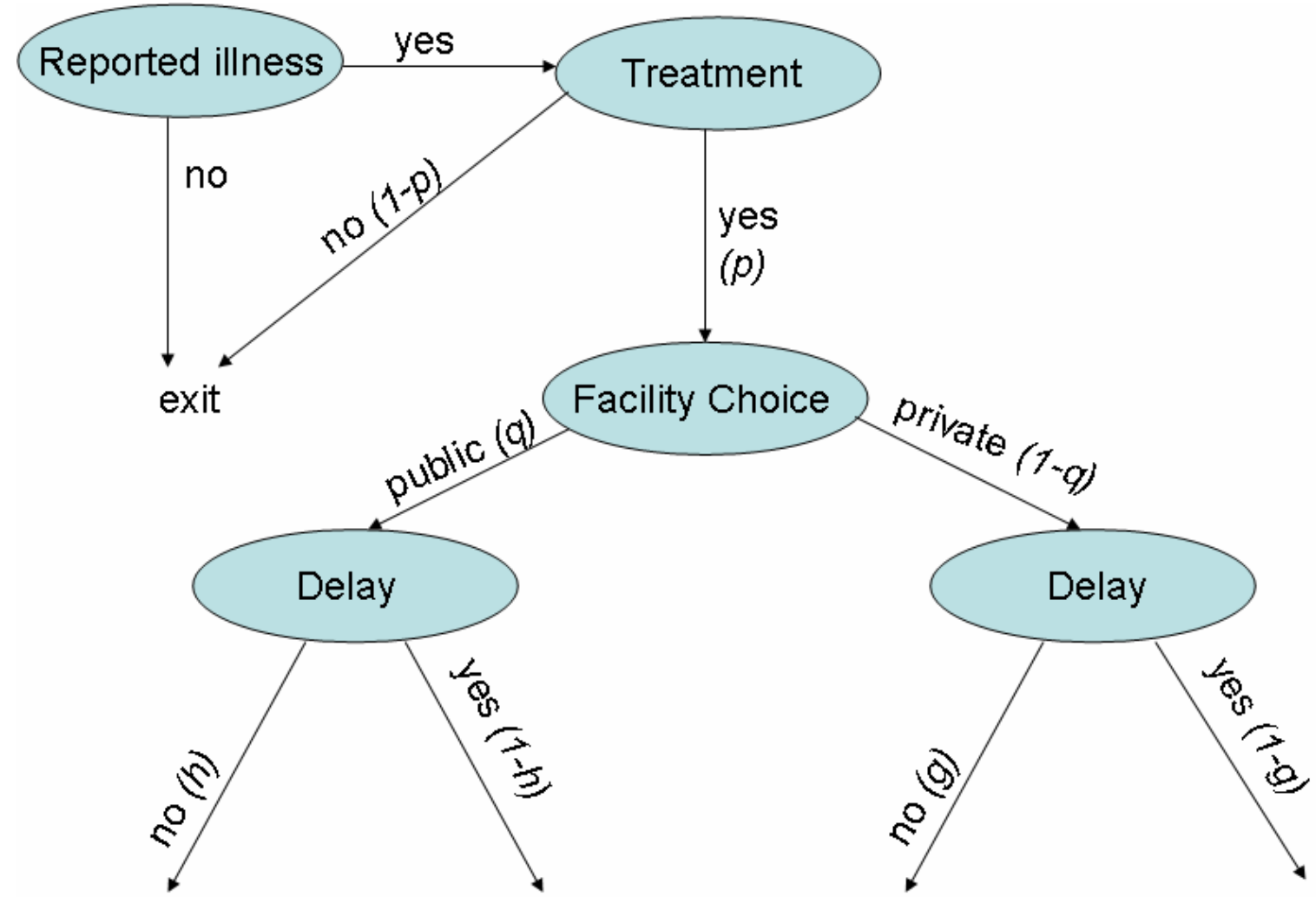

Figure 1. Health-seeking decisions pathway model (Conceptualization A) 


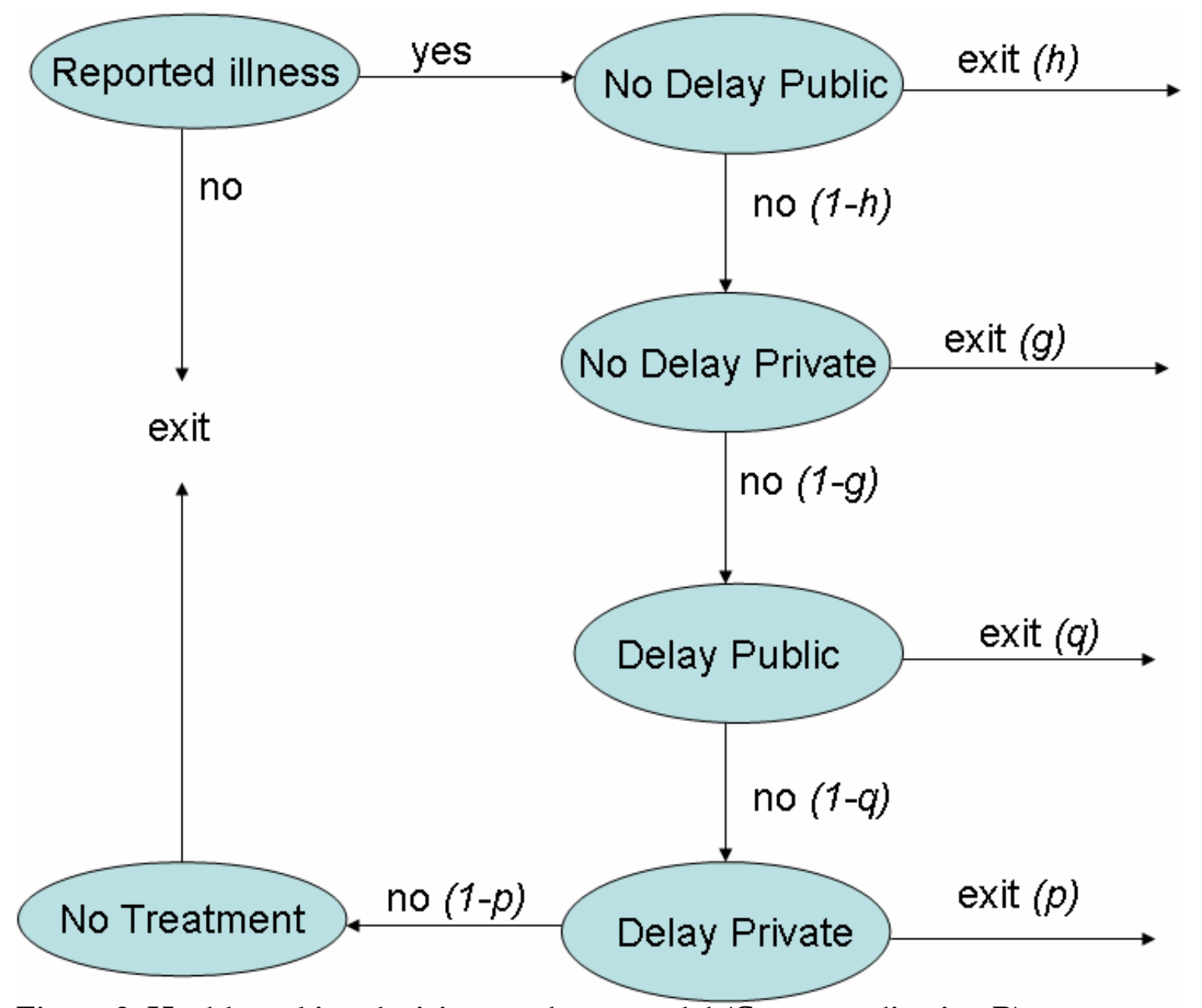

Figure 2. Health-seeking decisions pathway model (Conceptualization B) 
Table 1. Descriptive Statistics across health care decision trajectories (in percentages)

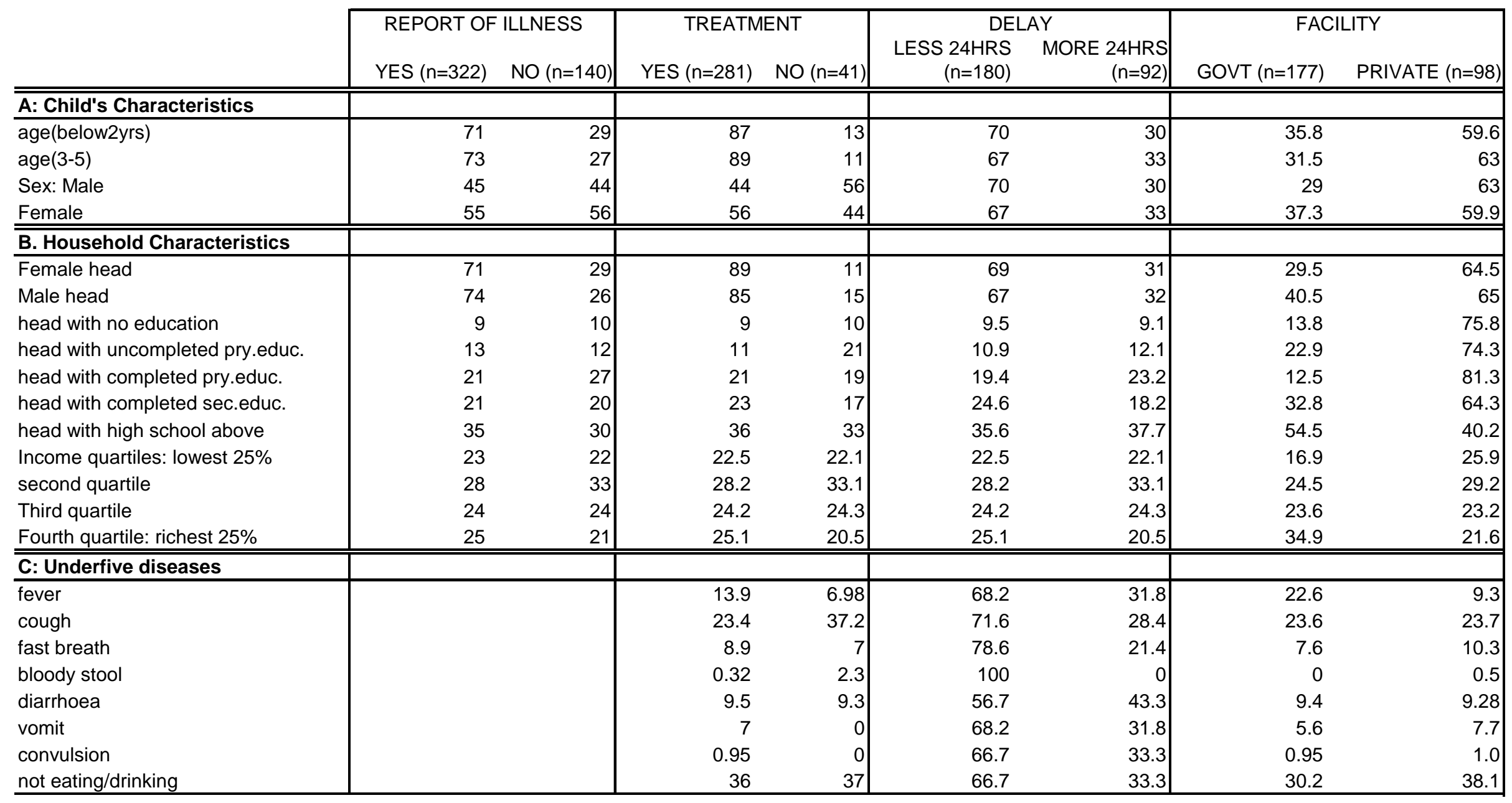


Table 2. Sequential Logit Estimation Results (Conceptualization A)

\begin{tabular}{|c|c|c|c|c|}
\hline $\begin{array}{l}\text { Decision Choice } \\
\text { Conditionality }\end{array}$ & $\begin{array}{c}\text { Treatment }(=1) \text { vs No } \\
\text { Treatment } \\
\text { No Conditioning }\end{array}$ & $\begin{array}{c}\text { Public (=1) vs Private } \\
\text { Conditional on } \\
\text { Treatment }\end{array}$ & $\begin{array}{c}\text { Immediate }(=1) \text { vs Delay } \\
\text { Conditional on Treated } \\
\text { Public }\end{array}$ & $\begin{array}{c}\text { Immediate }(=1) \text { vs Delay } \\
\text { Conditional on Treated } \\
\text { Private }\end{array}$ \\
\hline \multicolumn{5}{|l|}{ Independent Variables } \\
\hline Child Vomiting (=1) & $\begin{array}{l}1.237 \text { * } \\
(0.64)\end{array}$ & $\begin{array}{l}0.370 \\
(0.32)\end{array}$ & $\begin{array}{r}0.0497 \\
(0.42)\end{array}$ & $\begin{array}{l}-0.008 \\
(-0.60)\end{array}$ \\
\hline Child Feverish (=1) & $\begin{array}{l}0.843 \text { ** } \\
(0.38)\end{array}$ & $\begin{array}{l}0.586 \text { * } \\
(0.35)\end{array}$ & $\begin{array}{r}-0.42 \\
(-0.37)\end{array}$ & $\begin{array}{l}-1.895 \\
(-0.73)\end{array}$ \\
\hline Per Capita Expenditure (PCE) & $\begin{array}{l}1.371 \\
(0.85)\end{array}$ & $\begin{array}{l}-0.369 \\
(-0.72)\end{array}$ & $\begin{array}{l}0.286 \\
(0.96)\end{array}$ & $\begin{array}{l}-1.961 \\
(-1.47)\end{array}$ \\
\hline PCE squared & $\begin{array}{l}-0.097 \\
(-0.08)\end{array}$ & $\begin{array}{l}0.047 \\
(0.06)\end{array}$ & $\begin{array}{l}-0.024 \\
(-0.09)\end{array}$ & $\begin{array}{r}0.19 \\
(0.13)\end{array}$ \\
\hline Primary Education for Head & $\begin{array}{l}0.327 \\
(0.46)\end{array}$ & $\begin{array}{l}-1.223 * * * \\
(-0.40)\end{array}$ & $\begin{array}{l}-0.091 \\
(-0.39)\end{array}$ & $\begin{array}{l}2.051 \text { ** } \\
(0.89)\end{array}$ \\
\hline Prop. of Educated Females & $\begin{array}{l}2.108 \text { * } \\
(1.09)\end{array}$ & $\begin{array}{l}0.153 \\
(0.86)\end{array}$ & $\begin{array}{l}-0.376 \\
(-0.98)\end{array}$ & $\begin{array}{l}-4.61 \text { ** } \\
(-2.08)\end{array}$ \\
\hline Female Household Head $(=1)$ & $\begin{array}{l}0.901 \\
(0.41)\end{array}$ & $\begin{array}{l}-0.231 \\
(-0.30)\end{array}$ & $\begin{array}{l}-0.294 \\
(-0.38)\end{array}$ & $\begin{array}{l}-0.422 \\
(-0.58)\end{array}$ \\
\hline Size of Household & $\begin{array}{l}0.209 \\
(0.10)\end{array}$ & $\begin{array}{l}-0.061 \\
(-0.07)\end{array}$ & $\begin{array}{l}-0.014 \\
(-0.08)\end{array}$ & $\begin{array}{l}-0.291 \\
(-0.19)\end{array}$ \\
\hline Household Head Single $(=1)$ & $\begin{array}{l}-1.048 \text { *** } \\
(-0.41)\end{array}$ & $\begin{array}{l}0.259 \\
(0.31)\end{array}$ & $\begin{array}{l}0.107 \\
(0.37)\end{array}$ & $\begin{array}{l}0.213 \\
(0.62)\end{array}$ \\
\hline Working Females & $\begin{array}{l}0.209 \\
(0.42)\end{array}$ & $\begin{array}{l}0.909 \\
(0.31)\end{array}$ & $\begin{array}{l}0.125 \\
(0.39)\end{array}$ & $\begin{array}{l}0.181 \\
(0.66)\end{array}$ \\
\hline Constant & $\begin{array}{l}-5.52 \\
(-2.47)\end{array}$ & $\begin{array}{l}-0.627 \\
(-2.29)\end{array}$ & $\begin{array}{r}-1.19 \\
(-2.80)\end{array}$ & $\begin{array}{l}9.694 \text { * } \\
(5.19)\end{array}$ \\
\hline Observations & 313 & 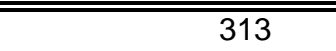 & 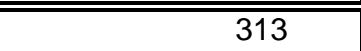 & 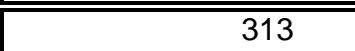 \\
\hline LR chi2(40) & 85.2 & 85.2 & 85.2 & 85.2 \\
\hline Log likelihood & -410.93 & -410.93 & -410.93 & -410.93 \\
\hline
\end{tabular}

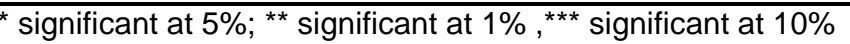

Standard errors in parentheses 
Table 3. Sequential Logit Estimation Results (Conceptualization B)

\begin{tabular}{|c|c|c|c|c|}
\hline $\begin{array}{l}\text { Decision Choice } \\
\text { Conditionality }\end{array}$ & $\begin{array}{c}\text { Treatment }(=1) \text { vs No } \\
\text { Treatment } \\
\text { No Conditioning }\end{array}$ & $\begin{array}{c}\text { Public }(=1) \text { vs Private } \\
\text { Conditional on } \\
\text { Treatment }\end{array}$ & $\begin{array}{c}\text { Immediate }(=1) \text { vs } \\
\text { Delay } \\
\text { Conditional on Treated } \\
\text { Public }\end{array}$ & $\begin{array}{c}\text { Immediate }(=1) \text { vs } \\
\text { Delay } \\
\text { Conditional on Treated } \\
\text { Private }\end{array}$ \\
\hline \multicolumn{5}{|l|}{ Independent Variables } \\
\hline Child Vomiting $(=1)$ & $\begin{array}{l}-0.190 \\
(-0.29)\end{array}$ & $\begin{array}{l}-0.043 \\
(-0.38)\end{array}$ & $\begin{array}{l}-0.216 \\
(-0.51)\end{array}$ & $\begin{array}{l}-2.069 \\
(-0.86)\end{array}$ \\
\hline Child Feverish $(=1)$ & $\begin{array}{l}-0.207 \\
(-0.28)\end{array}$ & $\begin{array}{l}-1.001 \\
(-0.36)\end{array}$ & $\begin{array}{l}-0.096 \\
(-0.43)\end{array}$ & $\begin{array}{l}-0.893 \\
(-0.64)\end{array}$ \\
\hline Per Capita Expenditure (PCE) & $\begin{array}{l}-0.052 \\
(-0.59)\end{array}$ & $\begin{array}{l}-1.621 \\
(-0.81)\end{array}$ & $\begin{array}{l}-2.606 \\
(-1.21)\end{array}$ & $\begin{array}{l}-0.908 \\
(-1.57)\end{array}$ \\
\hline PCE squared & $\begin{array}{l}0.008 \\
(0.05)\end{array}$ & $\begin{array}{l}0.151 \\
(0.07)\end{array}$ & $\begin{array}{l}0.238 \text { ** } \\
(0.11)\end{array}$ & $\begin{array}{r}0.0489 \\
(0.14)\end{array}$ \\
\hline Primary Education for Head & $\begin{array}{l}-0.754 \\
(-0.29)\end{array}$ & $\begin{array}{r}0.72 \\
(0.44)\end{array}$ & $\begin{array}{l}-0.614 \\
(-0.49)\end{array}$ & $\begin{array}{l}-0.344 \\
(-0.81)\end{array}$ \\
\hline Prop. of Educated Females & $\begin{array}{l}0.469 \\
(0.73)\end{array}$ & $\begin{array}{l}-3.052 \\
(-0.97)\end{array}$ & $\begin{array}{l}-1.722 \\
(-1.24)\end{array}$ & $\begin{array}{l}-2.325 \\
(-2.01)\end{array}$ \\
\hline Female Household Head (=1) & $\begin{array}{r}-0.21 \\
(-0.27)\end{array}$ & $\begin{array}{r}-0.62 \\
(-0.34)\end{array}$ & $\begin{array}{l}-0.530 \\
(-0.48)\end{array}$ & $\begin{array}{l}-1.055 \\
(-0.75)\end{array}$ \\
\hline Size of Household & $\begin{array}{l}-0.057 \\
(-0.06)\end{array}$ & $\begin{array}{l}-0.137 \\
(-0.08)\end{array}$ & $\begin{array}{l}-0.179 \\
(-0.11)\end{array}$ & $\begin{array}{l}-0.108 \\
(-0.20)\end{array}$ \\
\hline Household Head Single $(=1)$ & $\begin{array}{l}0.122 \\
(0.26)\end{array}$ & $\begin{array}{l}0.441 \\
(0.34)\end{array}$ & $\begin{array}{l}0.830 \text { * } \\
(0.46)\end{array}$ & $\begin{array}{l}1.143 \\
(0.73)\end{array}$ \\
\hline Working Females & $\begin{array}{l}0.378 \\
(0.28)\end{array}$ & $\begin{array}{l}-0.172 \\
(-0.35)\end{array}$ & $\begin{array}{l}0.582 \\
(0.49)\end{array}$ & $\begin{array}{l}-1.507 \text { ** } \\
(-0.74)\end{array}$ \\
\hline Constant & $\begin{array}{r}1.091 \\
(1.79) \\
\end{array}$ & $\begin{array}{l}7.803^{* * *} \\
(2.58)\end{array}$ & $\begin{array}{l}9.017 \text { ** } \\
(3.60)\end{array}$ & $\begin{array}{r}7.108 \\
(5.19) \\
\end{array}$ \\
\hline Observations & 313 & 313 & 313 & 313 \\
\hline LR chi2(40) & 78.58 & 78.58 & 78.58 & 78.58 \\
\hline Log likelihood & -432.47 & -432.47 & -432.47 & -432.47 \\
\hline
\end{tabular}

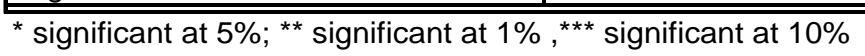

Standard errors in parentheses 